\title{
Numerical Investigation of Fatigue Behavior of Non-patched and Patched Aluminum/Composite Plates
}

\author{
Hamit Adin ${ }^{* *}\left(\mathbb{D}\right.$, Zeyni Sağlam² $\mathbb{D}^{D}$, Mehmet Şükrü Adin³ \\ 1,2,3 Department of Mechanical Engineering, University of Batman, Batman, Turkey
}

\begin{abstract}
In this study, the fatigue behavior of composite patched and non-patched $\mathrm{Al} 5083$ aluminum plates was numerically investigated. Al 5083 Aluminum plates with semi-circular notched (2, 3 and $4 \mathrm{~mm}$ long cracked) and "V" notched $\left(30^{\circ}, 45^{\circ}\right.$ and $60^{\circ}$ angled) were used in the analyzes. Mechanical properties of $\mathrm{Al} 5083$ Aluminum plate, DP460 type adhesive of produced by $3 \mathrm{M}$ and $\left[0^{\circ}\right]_{8}$ glass fiber reinforced composite patch material was used for the study. The Finite Element Method was applied for numerical study. Numerical analyzes were performed with the Ansys version 15.0 Workbench Package program. As a result of the numerical study, the highest fatigue life $(1593.2 \mathrm{~N})$ is seen on the $30^{\circ}$ angled "V" notched and patched specimen. However, the fatigue life in non-patched specimen $\left(30^{\circ}\right.$ angled " $\mathrm{V}$ " notched) was found to be $277.69 \mathrm{~N}$. Thus, the study revealed that the composite patch's contribution is very important.
\end{abstract}

Keywords: Aluminum, Composite, Patch, Notch, Crack, Fatigue analysis

\section{INTRODUCTION}

Aluminum and composite materials are used extensively in different industrial areas such as aviation, space, automotive and marine. Because of their intense use, experimental research is required to develop, as strength and repair, these materials. Experimental research to develop these materials requires significant financial resources and time. Therefore, there has been interest in numerical analysis. The main reason for interest in numerical analysis is that it is very close to experimental results. In addition, through numerical analysis programs, it is possible to find solutions to the damage that may occur in these materials in advance [1-11]. There are many numerical studies on different types of Aluminum and Composite materials $[3,6,8,9,11]$. However, these materials are used in many different areas. Therefore, every study on these materials is important.

Can C. [12] investigated experimentally and numerically the fiberglass epoxy composite patches applied on damaged $\mathrm{Al}$ 2024 T3 aluminum sheets. In study, the critical lines were determined and the stress distributions on the samples along these lines were examined. His study showed that the numerical results are very close to the experimental results. In a study performed by Ahmet S. [13], the Al 5754 aluminum material repaired with composite patch were experimentally and numerically investigated. As a result of his investigation, he stated that the stresses on double-sided composite patched aluminum sheets are less. Uğur S. [14] experimentally performed the tensile and bending tests of the Al-2024 T3 aluminum adherend material repaired with a graphite/ epoxy patch and compared the results with numerical analysis. He stated that the experimental and numerical analysis were in harmony as a result of the examination. Osman A. [15] investigated repairing damaged glass fiber reinforced epoxy composite plates by using composite patches. In the study, the effect of patch size and patch number changes on flexural stress behavior was investigated experimentally and numerically. As a result of the study, he stated that numerical analysis results and experimental results were very close. Mehmet R. [16] examined experimentally and numerically by repairing elliptical damaged glass fiber reinforced composite plates with the same material. In his investigation, he showed that the tensile stresses of the repaired glass fiber reinforced composite plates were compatible with the numerical ones. Abdulkerim P. [17] examined the repair performance by subjecting the repaired composite plates to a tensile test. The result of the research indicated that the experimental and numerical results were compatible.

The harmony of the results of the experimental and numerical studies mentioned above increases the importance of numerical studies. Therefore, in our study, the fatigue behavior of composite patched and non-patched Al 5083 aluminum plates (semi-circular and "V" notched) was numeri- 
cally investigated. Thus, the effects of both patch and notch shapes on fatigue life were found.

\section{MATERIAL AND METHOD}

In our study, numerical analyzes were performed using the Finite Element Method. Numerical analyzes were performed with the Ansys version 15.0 Workbench Package program $[18,19]$. As materials, Al 5083 aluminum plate, $\left[0^{\circ}\right] 8$ glass fiber reinforced composite patch and DP460 type adhesive of produced by $3 \mathrm{M}$ were preferred. The mechanical properties of these materials were used in numerical analysis. The mechanical properties of $\mathrm{Al} 5083$ Aluminum plate, $\left[0^{\circ}\right] 8$ glass fiber reinforced composite patch and DP-460 adhesive materials used in the analyzes are given in Table 1, Table 2 and Table 3, respectively [20-22].

Table 1. Mechanical properties of Al 5083 Aluminum plate [20].

\begin{tabular}{|c|c|}
\hline Elasticity module & $70000 \mathrm{MPa}$ \\
\hline Poisson ratio & 0.3897 \\
\hline Tensile strength & $345 \mathrm{MPa}$ \\
\hline Yield strength & $270 \mathrm{MPa}$ \\
\hline Thermal conductivity & $204 \mathrm{~W} /(\mathrm{m} . \mathrm{K})$ \\
\hline Thermal expansion coefficient & $2.4 \mathrm{e}-0051 / \mathrm{K}$ \\
\hline Mass density & $2660 \mathrm{~kg} / \mathrm{m}^{3}$ \\
\hline Specific heat & $940 \mathrm{~J} /(\mathrm{kg} . \mathrm{K})$ \\
\hline
\end{tabular}

Table 2. Mechanical properties of $\left[0^{\circ}\right]_{8}$ glass fiber reinforced composite patch [21].

\begin{tabular}{|c|c|}
\hline$E_{1}$ & $40510 \mathrm{MPa}$ \\
\hline$E_{2}=E_{3}$ & $13960 \mathrm{MPa}$ \\
\hline$G_{12}$ & $3100 \mathrm{MPa}$ \\
\hline$G_{13}=G_{23}$ & $1100 \mathrm{MPa}$ \\
\hline$\vartheta_{12}$ & 0.22 \\
\hline$\vartheta_{13}=\vartheta_{23}$ & 0.15 \\
\hline
\end{tabular}

Table 3. Mechanical properties of 3M brand DP460 type industrial adhesive [22].

\begin{tabular}{|c|c|}
\hline Adhesive thickness & $0.25 \mathrm{~mm}$ \\
\hline Shear stress & $23.99 \mathrm{MPa}$ \\
\hline Shear strength & $33.35 \mathrm{MPa}$ \\
\hline Shear module & $560 \mathrm{MPa}$ \\
\hline Elasticity Module & $2077.1 \mathrm{MPa}$ \\
\hline Poisson's ratio & 0.38 \\
\hline Tensile strength & $44.616 \mathrm{MPa}$ \\
\hline
\end{tabular}

In the study, $\mathrm{Al} 5083$ Aluminum plates with semi-circular notched (with 2, 3 and 4 mm cracks) or "V" shaped notches $\left(30^{\circ}, 45^{\circ}\right.$ and $60^{\circ}$ angled) were analyzed non-patched or patched. As patch material, $\left[0^{\circ}\right]_{8}$ glass fiber reinforced composites were used. In numerical study, the effect of nonpatched and patched aluminum plates on fatigue behaviors was investigated. Dimensions of Al 5083 Aluminum plates used in numerical studies are given in Fig. 1 and Fig. 2.

As seen in Fig. 1, Al 5083 Aluminum plates have semi-circular notch on one and both sides and 2, 3 and $4 \mathrm{~mm}$ long cracks advanced towards the interior.

As seen in Fig. 2, Al 5083 Aluminum plates have notches on one and both sides, these notches have $6 \mathrm{~mm}$ length and $30^{\circ}$, $45^{\circ}$ and $60^{\circ}$ angles. Dimensions of $\left[0^{\circ}\right]_{8}$ glass fiber reinforced composite patch used in numerical analysis are given in Fig. 3.

As a result of the literature review, the thickness of the adhesive was selected as $0.25 \mathrm{~mm}$ [23-25].

3-Dimensional pictures of the materials used in numerical analysis are given in Fig. 4.
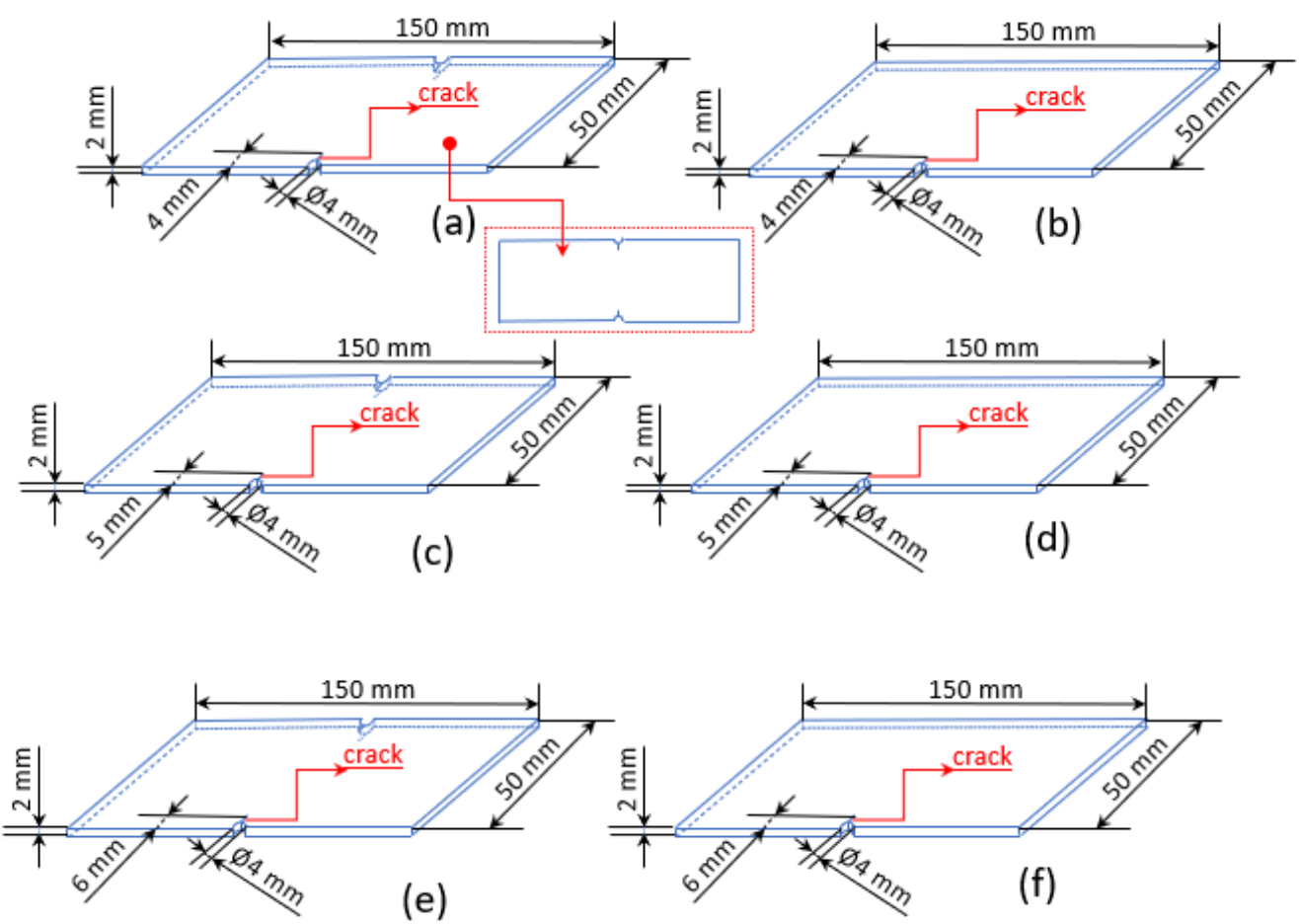

Figure 1. Dimensions of Al 5083 Aluminum plates with $2 \mathrm{~mm}(\mathrm{a}, \mathrm{b}), 3 \mathrm{~mm}(\mathrm{c}, \mathrm{d})$ and $4 \mathrm{~mm}(\mathrm{e}, \mathrm{f})$ cracks starting from the semi-circular notch (single and double sided). 

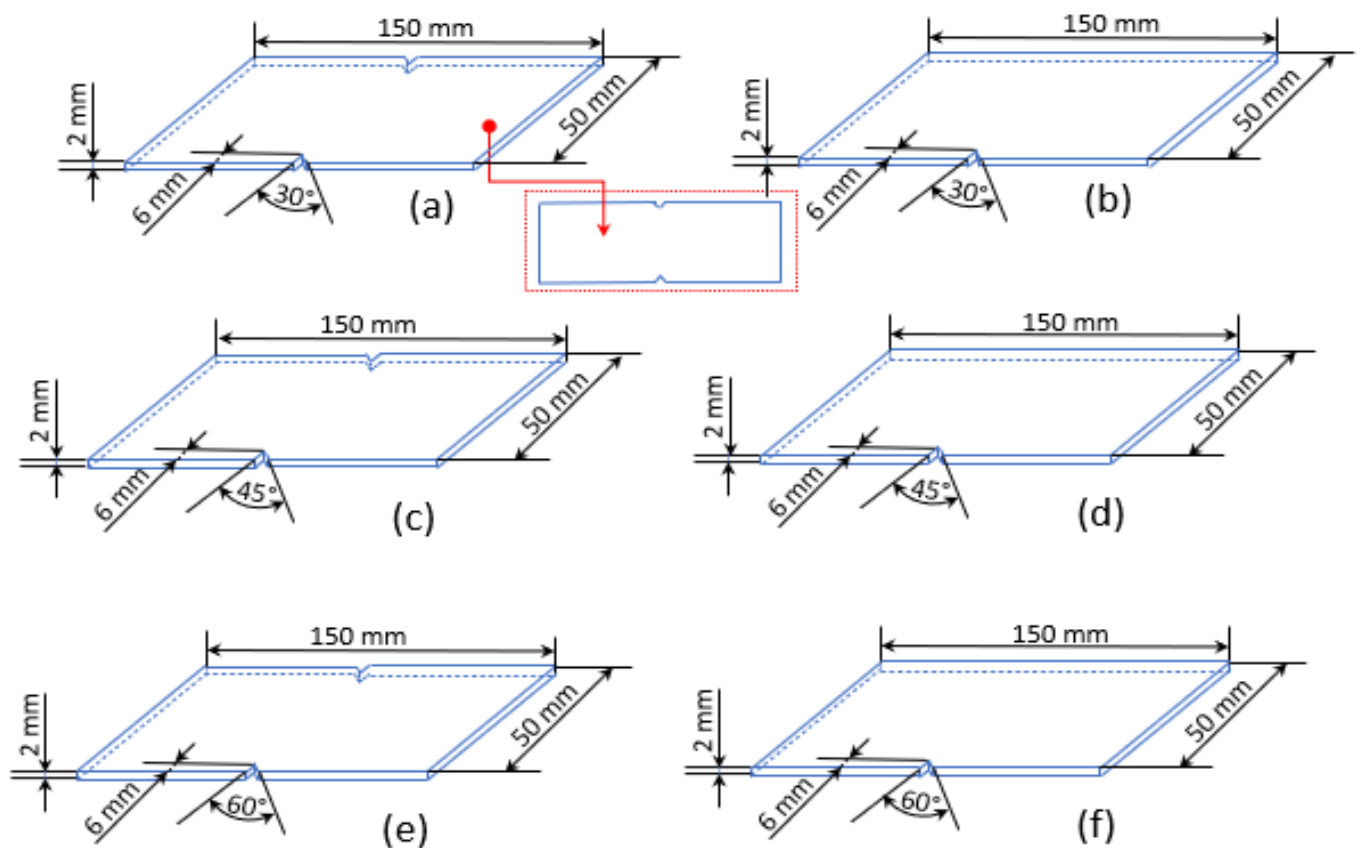

Figure 2. Dimensions of Al 5083 plates with notch length $6 \mathrm{~mm}$, notch angles $30^{\circ}(\mathrm{a}, \mathrm{b}), 45^{\circ}(\mathrm{c}, \mathrm{d})$, and $60^{\circ}(\mathrm{e}, \mathrm{f})$ (single and double sided).

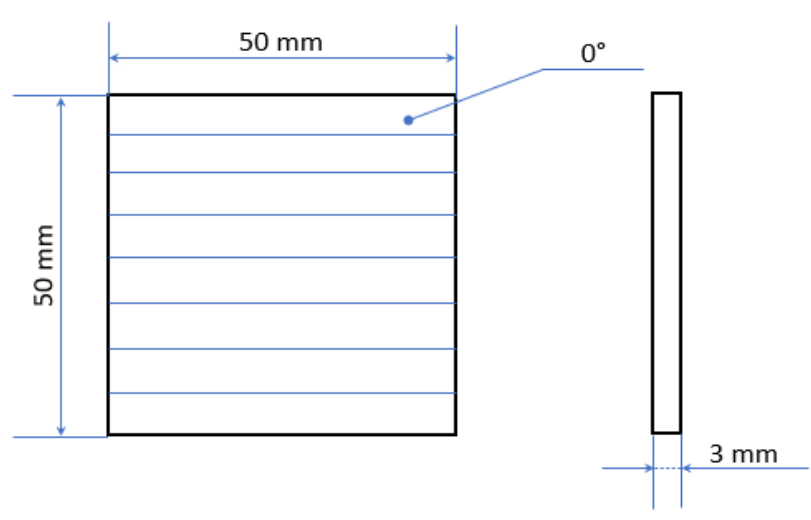

Figure 3. Dimensions of $\left[0^{\circ}\right]_{8}$ glass fiber reinforced composite patch.

The materials, whose technical drawings were prepared first, were drawn in 3D using the Solidworks program, and then transferred to the Ansys Workbench 15.0 Package program. In the study, the fatigue lives, Von-mises stresses and deformations of the materials were investigated by applying tensile-compression load $(R=-1)$. One end of the sample is modeled in a fixed support state. At the other end, pressure was applied based on $45 \%$ of the yield stress value of the $\mathrm{Al}$ 5083 aluminum plate sample. While the yield value of the Al 5083 Aluminum material, which is the analysis sample, is $270 \mathrm{MPa}$, tensile-compression loads were applied with a value of $121.5 \mathrm{MPa}$, which is $45 \%$ of this value. Pressure was applied directly opposite the fixed end. In Ansys, adding material to the contact parts of the joint (a), the screen accessed with the model (b), determination of the support and pressure points (c) and the mesh applied (d) are given in Fig. 5.

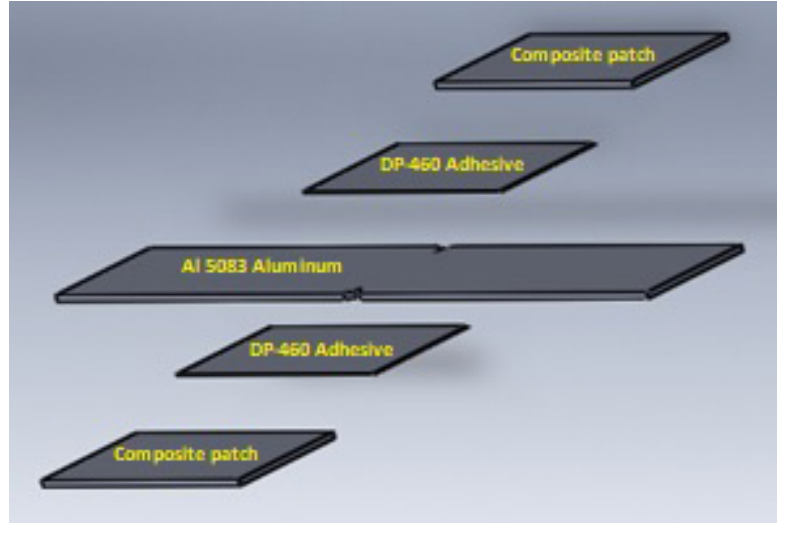

(a)

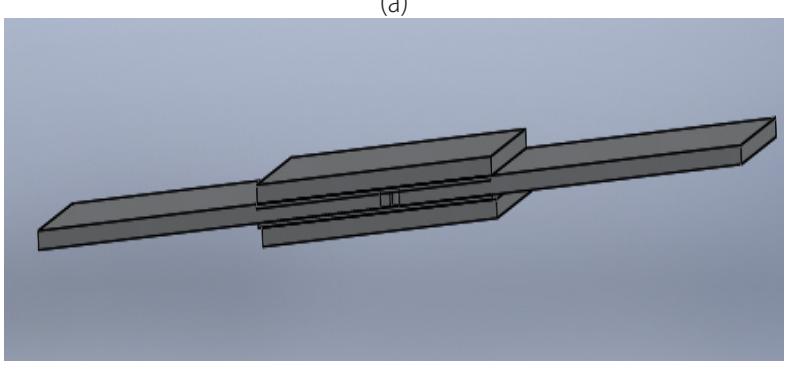

(b)

Figure 4. 3D pictures of materials before (a) and after (b) joining.

The number of elements and nodes of single and double sided, semi-circular notched and cracked (with 2, 3 and $3 \mathrm{~mm}$ ) samples after mesh structure are given in Table 4. 

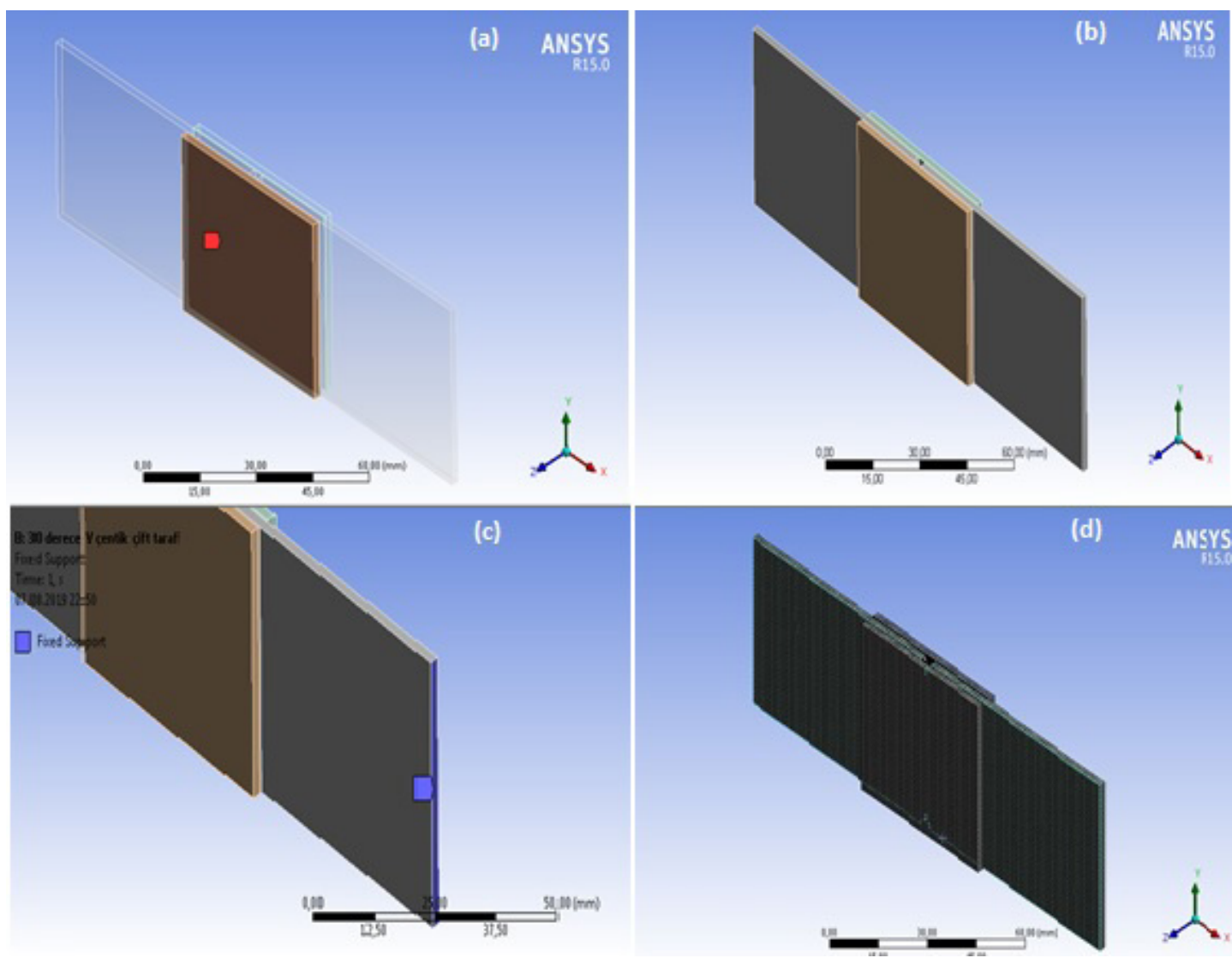

Figure 5. Pictures of adding material to the contact parts of the joint (a), the screen accessed with the model (b), determination of the support and pressure points (c) and the mesh applied (d).
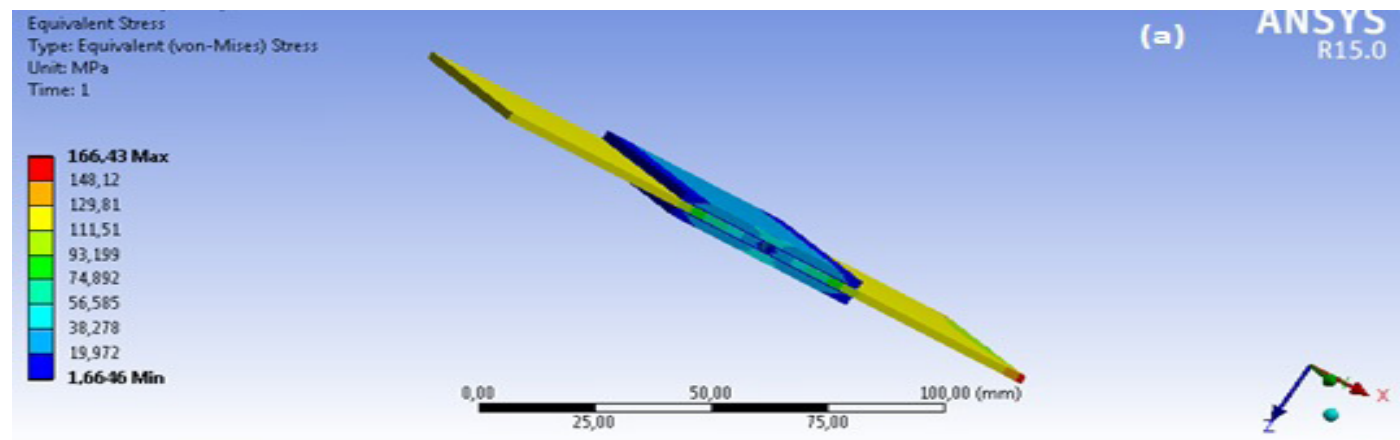

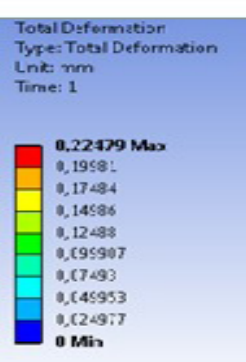

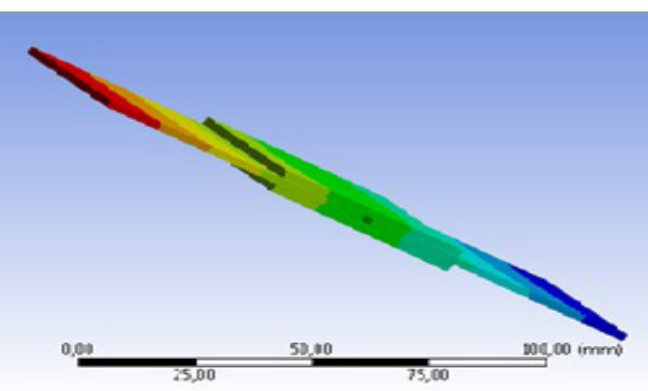

(b)
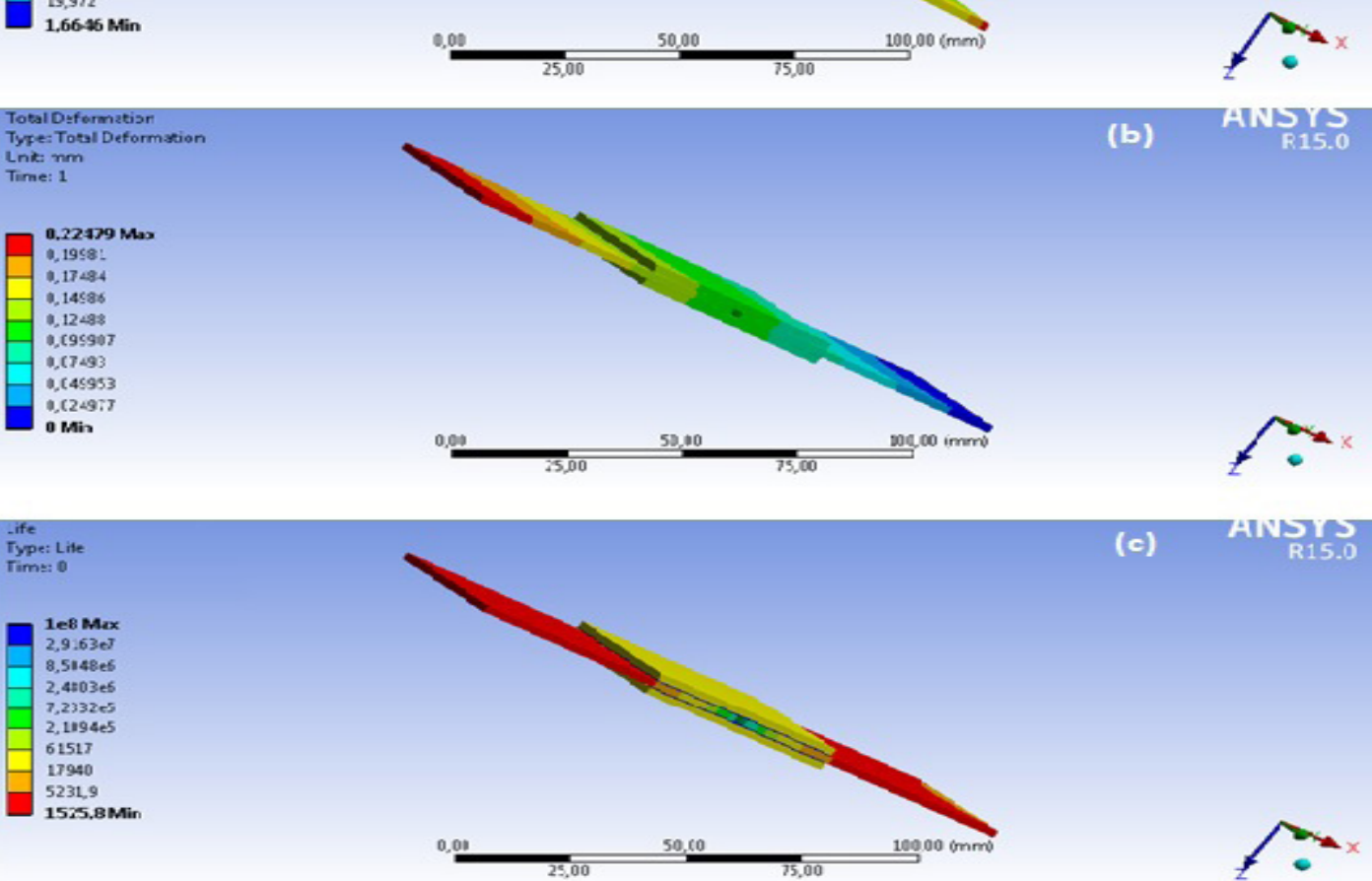

Figure 6. Pictures of Von-mises stress analysis (a), total deformation analysis (b) and fatigue life analysis (c) of the joints. 
Table 4. The number of elements and nodes of single and double sided, semi-circular notched and cracked (with 2,3 and $3 \mathrm{~mm}$ ) samples.

\begin{tabular}{|c|c|c|c|c|c|}
\hline \multirow{2}{*}{$\begin{array}{c}\text { Crack } \\
\text { length }\end{array}$} & & \multicolumn{4}{|c|}{ Semi-circular notches and cracks } \\
\hline & & One sided & Double-sided \\
\hline \multirow{2}{*}{$2 \mathrm{~mm}$} & & Non-patched & Patched & Non-patched & Patched \\
\cline { 2 - 6 } & Elements & 7548 & 102548 & 15172 & 110172 \\
\hline \multirow{2}{*}{$3 \mathrm{~mm}$} & Nodes & 53879 & 695099 & 85187 & 726407 \\
\cline { 2 - 6 } & Elements & 7560 & 102560 & 15276 & 110276 \\
\hline \multirow{2}{*}{$4 \mathrm{~mm}$} & Nodes & 53953 & 695173 & 85727 & 726947 \\
\cline { 2 - 6 } & Elements & 7584 & 102584 & 15194 & 110194 \\
\hline & Nodes & 54126 & 695346 & 85332 & 726552 \\
\hline
\end{tabular}

The number of elements and nodes of the samples with single and double sided "V" notched (30, 45 and 60 angled) after the mesh structure are given in Table 5.

Von-mises stress analysis (a), total deformation analysis (b) and fatigue life analysis (c) of the joints in the study are given in Fig. 6.

\section{RESULTS AND DISCUSSION}

\subsection{Fatigue life}

The results of fatigue analysis applied to $\mathrm{Al} 5083$ aluminum plates (non-patched and patched) with semi-circular notches (single and double sided) and cracks (2, 3 and $4 \mathrm{~mm}$ ) are given in Table 6. Here, $\mathrm{N}$ symbolizes the number of cycles.

\begin{tabular}{|} 
Table 6. The results of fatigue analysis. \\
\begin{tabular}{|c|c|c|c|c|}
\hline \multirow{2}{*}{$\begin{array}{c}\text { With semi-circular } \\
\text { notch and crack }\end{array}$} & \multicolumn{3}{|c|}{ Number of cycles (N) } \\
\cline { 2 - 5 } & \multicolumn{3}{|c|}{ Single sided } & \multicolumn{2}{|c|}{ Double sided } \\
\cline { 2 - 5 } Crack length & Non-patched & Patched & Non-patched & Patched \\
\hline $2 \mathrm{~mm}$ & 347.67 & 1267 & 428.68 & 1266.70 \\
\hline $3 \mathrm{~mm}$ & 321.80 & 1266.90 & 373.86 & 1266.40 \\
\hline $4 \mathrm{~mm}$ & 265.04 & 1266.80 & 323.20 & 1266.30 \\
\hline
\end{tabular}
\end{tabular}

As can be seen in Table 6, in numerical analysis, the fatigue life of the patched samples was found to be quite high (about 3.5 times on average). It has been observed that the increase in the length of the cracks $(2,3$ and $4 \mathrm{~mm})$ negatively affected the fatigue life. It has been observed that samples with

Table 5. The number of elements and nodes of the samples with single and double sided "V" notched (30, 45 and 60 angled).

\begin{tabular}{|c|c|c|c|c|c|}
\hline \multirow[t]{3}{*}{ "V" Notch angle } & & \multicolumn{4}{|c|}{ "V" notched } \\
\hline & & \multicolumn{2}{|c|}{ One sided } & \multicolumn{2}{|c|}{ Double-sided } \\
\hline & & Non-patched & Patched & Non-patched & Patched \\
\hline \multirow[t]{2}{*}{$30^{\circ}$ Angled } & Elements & 71215 & 166215 & 15354 & 110354 \\
\hline & Nodes & 128928 & 770148 & 86148 & 727368 \\
\hline \multirow[t]{2}{*}{$45^{\circ}$ Angled } & Elements & 70672 & 165672 & 15186 & 110186 \\
\hline & Nodes & 128031 & 769251 & 85176 & 726396 \\
\hline \multirow[t]{2}{*}{$60^{\circ}$ Angled } & Elements & 15028 & 110028 & 15126 & 110126 \\
\hline & Nodes & 84283 & 725503 & 84846 & 726066 \\
\hline
\end{tabular}

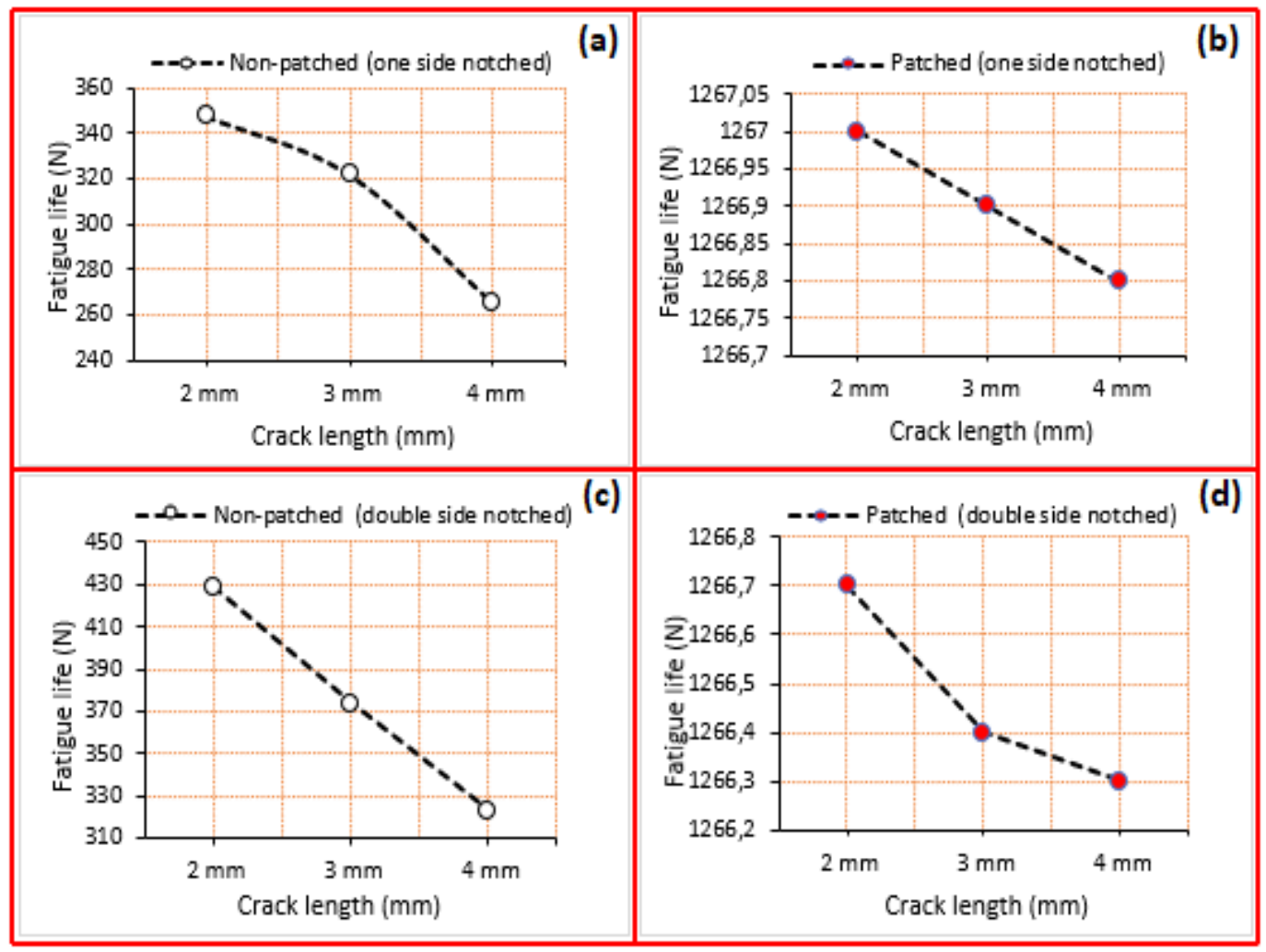

Figure 7. Fatigue lives of the samples. 


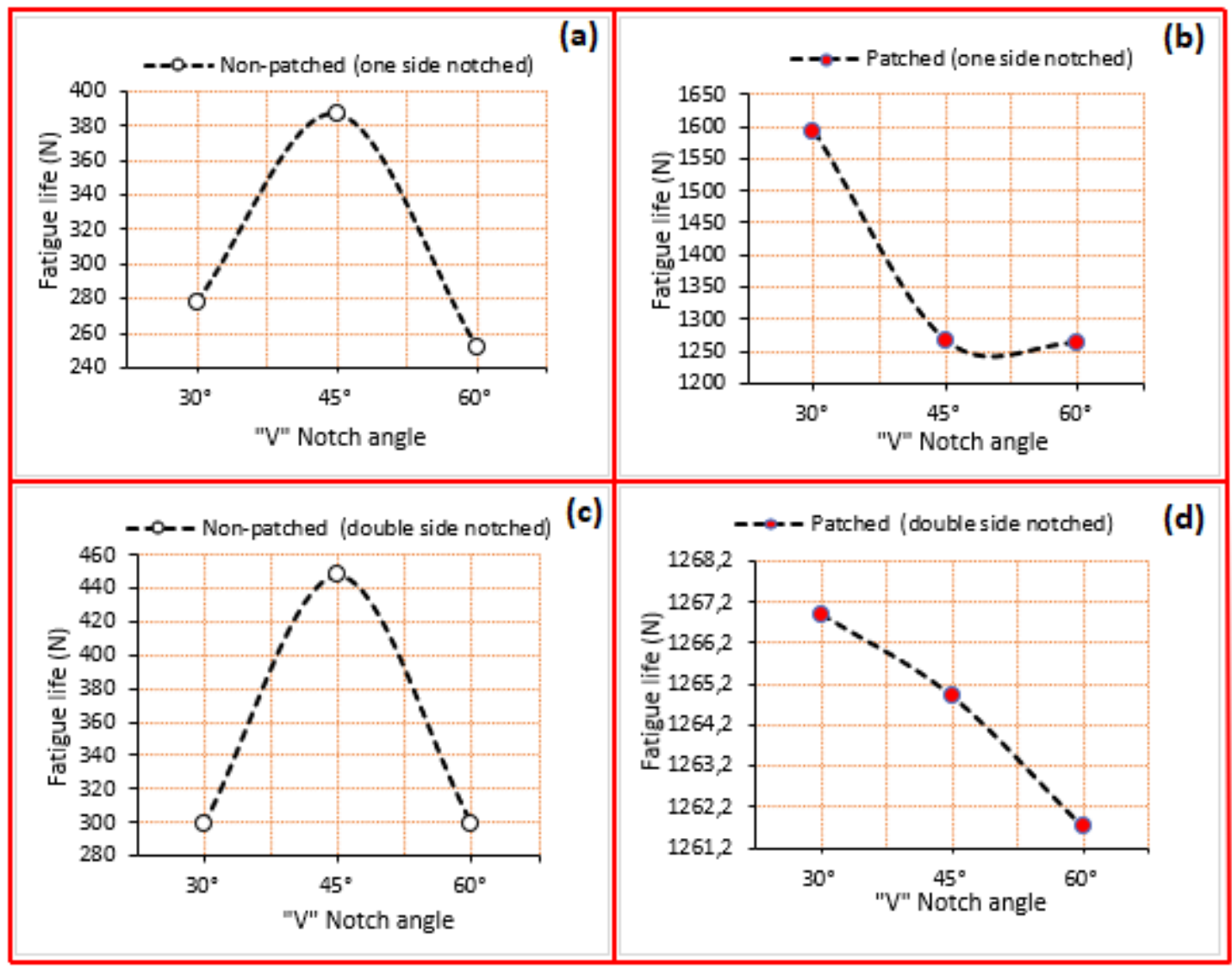

Figure 8. Fatigue lives of the samples.

Table 7. The results of fatigue life analysis.

\begin{tabular}{|c|c|c|c|c|}
\hline \multirow{3}{*}{$\begin{array}{l}\text { With "V" notch } \\
\text { Angle }\end{array}$} & \multicolumn{4}{|c|}{ Number of cycles $(N)$} \\
\hline & \multicolumn{2}{|c|}{ Single sided } & \multicolumn{2}{|c|}{ Double sided } \\
\hline & Non-patched & Patched & Non-patched & Patched \\
\hline $30^{\circ}$ & 277.69 & 1593.2 & 298.45 & 1266.90 \\
\hline $45^{\circ}$ & 387.11 & 1265.5 & 448.04 & 1264.90 \\
\hline $60^{\circ}$ & 251.66 & 1262.3 & 298.70 & 1261.70 \\
\hline
\end{tabular}

notches and cracks on one side have lower fatigue life than samples with notches and cracks on both sides.

As can be seen in Fig. 7 a, the increase in crack length caused a decrease in fatigue life. The fatigue lives of the notched (one-sided) and non-patched samples decreased due to increased crack length (Fig. 7 c). Fig. 7 b shows a decrease in fatigue life with increasing crack size. However, the fatigue lives of the samples are very close to each other in every crack size. When a comparison is made between Fig. 7 a and Fig. 7 b, it is seen that the fatigue life of the patched samples is quite high (Fig. 7 b and d). Therefore, it has shown that composite patches applied to semi-circular notched and cracked aluminum samples are very successful. In patched samples, as a result of the absorption of the applied load by the patches, the fatigue life has increased and the effect of crack lengths has been reduced to negligible. The linearity of the graph in samples with cracks on one side is due to the similarity of damage in one region of the load.

The results of the fatigue life analysis applied to single and double sided " $\mathrm{V}$ " notched $\left(30^{\circ}, 45^{\circ}\right.$ and $60^{\circ}$ angled) Al 5083 aluminum plates (Non-patched and patched) are given in Table 7.
As seen in Table 7, in numerical analysis, non-patched samples have a lower fatigue life than patched samples. The fatigue life of the sample with $30^{\circ}$ angled " $\mathrm{V}$ " notch (patched) on one side was found to be higher than all other samples. The fatigue life of the " $\mathrm{V}$ " notch with $30^{\circ}$ angled is quite high because it is patched with composite material and has the least notch dimensions.

The fatigue life graphs of the samples with " $\mathrm{V}$ " shaped $\left(30^{\circ}\right.$, $45^{\circ}$ and $60^{\circ}$ angled) notches on their single and double sides are given in Fig. 8. The most striking point in the graph is that the fatigue life of the $45^{\circ}$ angled "V" notch (nonpatched) sample is much higher than the $30^{\circ}$ and $60^{\circ}$ angled samples (Fig. 8 a and c). On the other hand, the fatigue lives of $30^{\circ}$ and $60^{\circ}$ angled (non-patched) samples are close to each other, but the fatigue life of the $30^{\circ}$ angled sample is longer (Fig. 8 a). The reason why the $45^{\circ}$ angled "V" notched (non-patched) sample has the highest fatigue life is that the stress creates agglomeration at this point (Fig. 8 a and c). In Fig. $8 \mathrm{~b}$ and d, the highest fatigue lives are at $30^{\circ}$ angled ("V" single notched) patched samples. On average, the fatigue lives of samples (patched) with "V" notches at $45^{\circ}$ and $60^{\circ}$ angles are close to each other (Fig. 8 b and d). It is also 
understood from the graphs that the fatigue life of the composite patch samples is quite high (Fig. $8 \mathrm{~b}$ and d). As seen in Fig. 8, samples with "V" notches on single and double sides are $30^{\circ}$ angled (patched) samples with the highest fatigue life. However, the highest fatigue life is the $30^{\circ}$ angled, one side notched and patched sample.

\subsection{Von-mises stresses}

The results of the Von-mises stresses of the non-patched and patched semi-circular notched (and cracked) samples are given in Table 8. As can be understood from Table 8, the lowest Von-mises stress values are seen in composite patched samples. When the samples (patched) with "V" semi-circular notches and cracks (2, 3 and $4 \mathrm{~mm}$ long) on one side are compared with the samples (patched) with "V" semi-circular notches and cracks (2, 3 and $4 \mathrm{~mm}$ long) on both sides, it is seen that the stress values are very close to each other. This shows that the effect of the composite patch on the stress is quite high. Since the semi-circular notch and crack are symmetrical on the part, it slightly reduces the stress value.

Table 8. The results of Von-mises stresses.

\begin{tabular}{|c|c|c|c|c|}
\hline \multirow{2}{*}{$\begin{array}{c}\text { With semi-circular } \\
\text { notch and crack }\end{array}$} & \multicolumn{4}{|c|}{ Von-mises stresses (MPa) } \\
\cline { 2 - 5 } & Single sided & \multicolumn{2}{c|}{ Double sided } \\
\cline { 2 - 5 } Crack length & Non-patched & Patched & Non-patched & Patched \\
\hline $2 \mathrm{~mm}$ & 291.09 & 178.30 & 264.43 & 178.32 \\
\hline $3 \mathrm{~mm}$ & 300.94 & 178.31 & 281.85 & 178.34 \\
\hline $4 \mathrm{~mm}$ & 325.65 & 178.31 & 300.39 & 178.34 \\
\hline
\end{tabular}

As can be seen from Fig. 9, while the stresses are less in patched samples, the stresses are higher in non-patched samples. Because, in composite-patched samples, some of the stresses are distributed over the composite and adhesive, so the stresses are less.

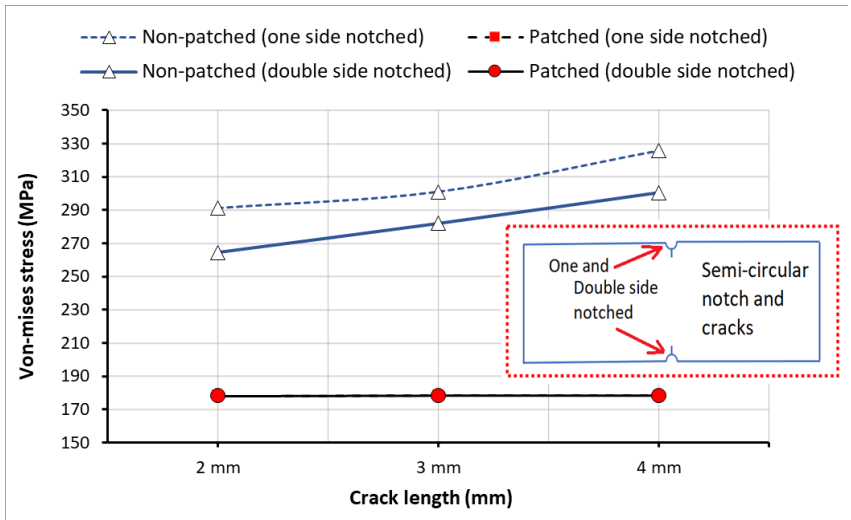

Figure 9. Von-mises stresses.

The results of the Von-mises stresses of the non-patched and patched "V" notched $\left(30^{\circ}, 45^{\circ}\right.$ and $60^{\circ}$ angled) samples are given in Table 9.
Table 9. The results of Von-mises stresses.

\begin{tabular}{|c|c|c|c|c|}
\hline \multirow{2}{*}{ With "V" notch } & \multicolumn{4}{|c|}{ Von-mises stresses (MPa) } \\
\cline { 2 - 5 } & \multicolumn{3}{|c|}{ Single sided } & \multicolumn{2}{c|}{ Double sided } \\
\cline { 2 - 5 } & $\begin{array}{c}\text { Non-patc- } \\
\text { hed }\end{array}$ & Patched & Non-patched & Patched \\
\hline $30^{\circ}$ & 319.71 & 163.67 & 310.53 & 178.31 \\
\hline $45^{\circ}$ & 277.41 & 178.38 & 258.8 & 178.41 \\
\hline $60^{\circ}$ & 332.24 & 178.54 & 310.43 & 178.57 \\
\hline
\end{tabular}

As seen in Table 9, the maximum stress values in patched samples are lower than non-patched samples. Because excessive stresses are distributed over the composite patch and adhesive. It is seen that the Von-mises stress values of nonpatched $45^{\circ}$ angled " $\mathrm{V}$ " notched joints are lower than those of $30^{\circ}$ and $60^{\circ}$ joints. It is seen that the $45^{\circ}$ angle is a critical value in " $\mathrm{V}$ " notched connections and it is beneficial. The symmetrical notches in non-patched samples are beneficial in terms of stresses.

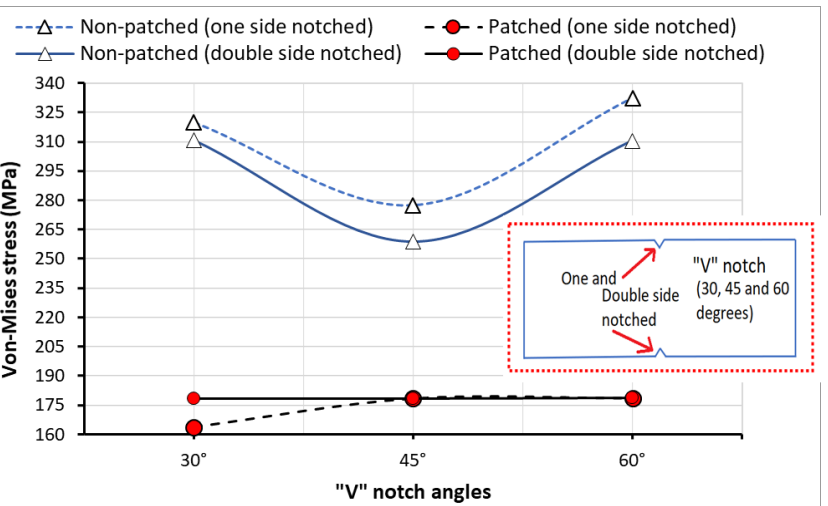

Figure 10. Von-mises stresses.

As can be seen from Fig. 10, while the stress is less in patched samples, it is higher in non-patched samples. Because, the composite patches have reduced the stresses.

\subsection{Deformations}

The results of the deformation of the non-patched and patched semi-circular notched (and cracked) samples are given in Table 10.

Table 10. The results of deformations.

\begin{tabular}{|c|c|c|c|c|}
\hline \multirow{2}{*}{$\begin{array}{c}\text { With semi-circular } \\
\text { notch and crack }\end{array}$} & \multicolumn{4}{|c|}{ Deformation (mm) } \\
\cline { 2 - 5 } & Non-patched & Patched & Non-patched & Patched \\
\cline { 2 - 5 } Crack length & & & & \\
\hline $2 \mathrm{~mm}$ & 0.26905 & 0.22522 & 0.26274 & 0.22451 \\
\hline $3 \mathrm{~mm}$ & 0.27571 & 0.22607 & 0.26513 & 0.22479 \\
\hline $4 \mathrm{~mm}$ & 0.28411 & 0.2262 & 0.26811 & 0.22475 \\
\hline
\end{tabular}

As seen in Table 10, the deformation values in patched samples are lower than those non-patched. Because composite patches have helped prevent deformation in samples. In non-patched samples, deformation increased due to the increase in crack size. 


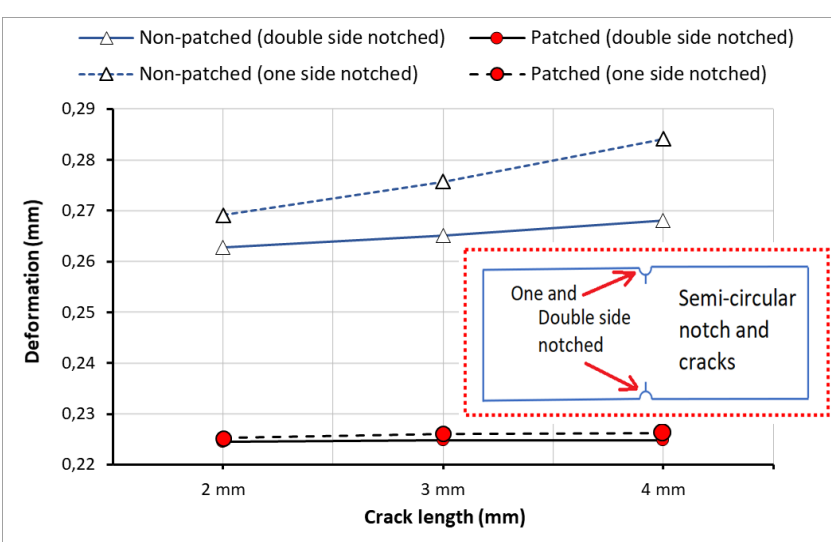

Figure 11. Deformation results.

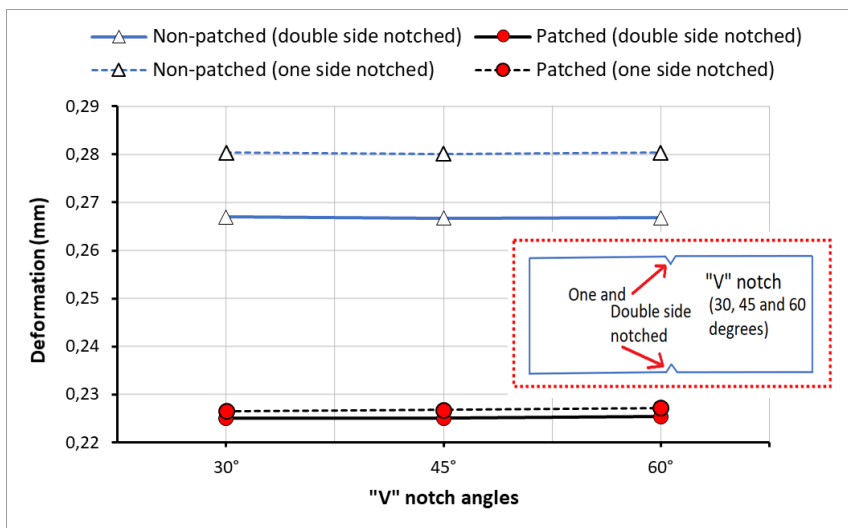

Figure 12. Deformation results.

As can be seen from Fig. 11, while the deformation is less in the patched samples, the deformation is higher in the nonpatched samples. Because, in composite-patched samples, some of the stresses are distributed over the composite and adhesive, so the deformation is less.

The results of the deformation of the non-patched and patched " $\mathrm{V}$ " notched $\left(30^{\circ}, 45^{\circ}\right.$ and $60^{\circ}$ angled) samples are given in Table 11.

\begin{tabular}{|c|c|c|c|c|}
\hline \multirow{2}{*}{ With "V" notch } & \multicolumn{4}{|c|}{ Deformation (mm) 11. The results of deformations. } \\
\cline { 2 - 5 } & \multicolumn{3}{|c|}{ Single sided } & \multicolumn{2}{c|}{ Double sided } \\
\cline { 2 - 5 } Angle & Non-patched & Patched & Non-patched & Patched \\
\hline $30^{\circ}$ & 0.28034 & 0.22650 & 0.26692 & 0.22505 \\
\hline $45^{\circ}$ & 0.28008 & 0.22672 & 0.26674 & 0.22499 \\
\hline $60^{\circ}$ & 0.28032 & 0.22720 & 0.26683 & 0.22532 \\
\hline
\end{tabular}

As seen in Fig. 13, while the deformation is less in the patched samples, the deformation is higher in the nonpatched samples.

In addition, it is seen from Fig. 12 that the deformations of the single and double notched connections are very close to each other. This revealed that the contribution of the composite patch is very important.

\section{CONCLUSIONS}

In our numerical study, Al 5083 aluminum plate, glass fiber reinforced composite patch and DP460 adhesive were used. Analyzes were performed using the Finite Element Meth- od. The Finite Element analyzes were made in Ansys Workbench. In the study, Al 5083 Aluminum plates with semi-circular notched (with 2, 3 and 4 mm cracks) or "V" shaped notches $\left(30^{\circ}, 45^{\circ}\right.$ and $60^{\circ}$ angles) were used non-patched or patched. In numerical study, the fatigue lives, Von-mises stresses and deformations of the materials were investigated. Obtained results are presented below.

The fatigue lives of the patched samples with semi-circular notches and cracks (2, 3 and $4 \mathrm{~mm}$ long) on both sides was very close to each other. Fatigue lives decreases in proportion to the increase in the length of the crack, but this decrease seems to have a very low value. The fatigue lives of the samples with one-sided semi-circular notches and cracks were seriously affected by the increase in crack length. It has been stated in the literature that smaller cracks increase the patch efficiency [26-28]. In the analysis, the deformation was mostly seen in the area of the crack. The same situation is observed in double sided semi-circular and cracked samples.

One side " $\mathrm{V}$ " notched $\left(30^{\circ}, 45^{\circ}\right.$ and $60^{\circ}$ angles) and patched specimens have been observed to increase fatigue life as the angle of the notch decreases. The highest fatigue life (1593.2 $\mathrm{N}$ ) is seen on the $30^{\circ}$ angled "V" notched and patched sample. However, the fatigue life in non-patched specimen $\left(30^{\circ}\right.$ angled "V" notched) was found to be $277.69 \mathrm{~N}$. As in the literature (in experimental studies with "V" notches), the positive effect of the composite patch on the fatigue life has been observed $[29,30]$. The same situation is observed in double sided "V" notched samples. However, it is seen that the fatigue lives of the samples with double sided "V" notches does not change much with the angle.

In non-patched samples, the highest fatigue life was found with a $45^{\circ}$ angled "V" notch on one side. Then, samples with $30^{\circ}$ and $60^{\circ}$ angles " $\mathrm{V}$ " notched are followed, respectively. The highest fatigue life of the non-patched specimens with "V" notches on double side is $45^{\circ}, 60^{\circ}$ and $30^{\circ}$, respectively.

The Von-mises stress and deformation values of single and double sided " $\mathrm{V}$ " notches $\left(30^{\circ}, 45^{\circ}\right.$ and $60^{\circ}$ angles) and semi-circular notches (with 2,3 and 4 mm cracks) were positively affected by the applied patches.

\section{REFERENCES}

[1] Carbas, R. J. C., Marques, E. A. S., \& da Silva, L. F. M. (2021). The influence of epoxy adhesive toughness on the strength of hybrid laminate adhesive joints. Applied Adhesion Science, 9(1), 1-14.

[2] Deghoul, N., Errouane, H., Sereir, Z., Chateauneuf, A., \& Amziane, S. (2019). Effect of temperature on the probability and cost analysis of mixed-mode fatigue crack propagation in patched aluminium plate. International Journal of Adhesion and Adhesives, 94, 53-63.

[3] Ergün, R. K., Adin, H., Şişman, A., \& Temiz, Ş. (2018). Repair of an aluminum plate with an elliptical hole using a composite patch. Materials Testing, 60(11), 1104-1110.

[4] Wu, C., Gunnion, A. J., Chen, B., \& Yan, W. (2015). Fatigue damage tolerance of two tapered composite patch configurations. Composite Structures, 134, 654-662. 
[5] Gong, X. J., Cheng, P., Aivazzadeh, S., \& Xiao, X. (2015). Design and optimization of bonded patch repairs of laminated composite structures. Composite Structures, 123, 292-300.

[6] Jian-Bin, H., Xu-Dong, L., \& Zhi-Tao, M. (2015). Fatigue behavior of thick center cracked aluminum plates repaired by two-sided composite patching. Materials \& Design, 88, 331-335.

[7] Saraç, I., Adin, H., \& Temiz, Ş. (2018). Experimental determination of the static and fatigue strength of the adhesive joints bonded by epoxy adhesive including different particles. Composites Part B: Engineering, 155, 92-103.

[8] Chung, K. H., \& Yang, W. H. (2003). A study on the fatigue crack growth behavior of thick aluminum panels repaired with a composite patch. Composite Structures, 60(1), 1-7.

[9] Maligno, A. R., Soutis, C., \& Silberschmidt, V. V. (2013). An advanced numerical tool to study fatigue crack propagation in aluminium plates repaired with a composite patch. Engineering Fracture Mechanics, 99, 62-78.

[10] Fekirini, H., Bouiadjra, B.B., Belhouari, M., Boutabout, B. \& Serier, B., (2008). Numerical analysis of the performances of bonded composite repair with two adhesive bands in aircraft structures. Composite structures, 82(1),84-89.

[11] Adin, M.Ş., Kılıçkap, E. (2021). Strength of double-reinforced adhesive joints. Materials Testing, 63(2), 176-181.

[12] Canbolat, C. (2018). Repairement of Al 2024 T3 plates by means of fiberglass composite patches, Master thesis, Kahramanmaras Sutcu Imam University, Turkey.

[13] Saylık, A. (2016). The stress analysis of aluminum plates repaired with composite patch, Master thesis, Firat University, Turkey.

[14] Soy, U. (2005). The finite element analysis of bonded repair with composite patch, Master thesis, Sakarya University, Turkey.

[15] Ahlatl, O. (2018). The expiremential and numerical investigation of the effects of dimension and number of layers of patches on bending stress behaviour of repairing composire plates having elliptical damage, Master thesis, Kahramanmaras Sutcu Imam University, Turkey.

[16] Ramazanoğlu, M. (2018). Experimental and numerical investigation of the effects of dimensions and number of layers of patches on tensile stress behaviour of repairing composite plates having elliptical damage, Master thesis, Kahramanmaraş Sutcu Imam University, Turkey.

[17] Parlamış, A. (2016). Investigation of patch repair performance for damaged composites pin loaded joint, Master thesis, Firat University, Turkey.

[18] ANSYS, (2014). ANSYS version R15 Canonsburg Pennsylvania, PA, USA. ANSYS Inc.

[19] Lee, H.-H., (2019). Finite Element Simulations with ANSYS Workbench 2019. SDC Publications.

[20] SolidWorks, (2013). Solidworks Software, SolidWorks Material Library. Dassault Systèmes, France. 3DExperience.

[21] Kiral, B.G. (2010). Effect of the clearance and interference-fit on failure of the pin-loaded composites. Materials \& Design, 31(1), 85-93.

[22] Aydın, M.D., Akpınar, S., Erdoğan, S., Adnan, Ö. (2015). Determination of Mechanical Properties of Structural Adhesives From Adhesively Bonded Joints Subjected to Shear Load. Mühendis ve Makina, 56(668), 48-55.

[23] Sadeghi, M., Zimmermann, J., Saravana, K., Gabener, A., Dafnis, A., Schröder, K. (2020). Influence of fracture envelope on FE failure load prediction of adhesively bonded joints by using mixed mode bending tests. Procedia Structural Integrity, 28, 1601-1620.

[24] Nezhad, H.Y., Stratakis, D., Ayre, D., Addepalli, S., Zhao, Y. (2018). Mechanical performance of composite bonded joints in the presence of localised process-induced zero-thickness defects. Procedia Manufacturing, 16, 91-98.

[25] Adin, H. (2012). The effect of angle on the strain of scarf lap joints subjected to tensile loads. Applied Mathematical Modelling, 36(7), 2858-2867.

[26] Baker, A. (1999). Bonded composite repair of fatigue-cracked primary aircraft structure. Composite structures, 47(1-4), 431-443.

[27] Seo, D.-C., Lee, J.-J. (2002). Fatigue crack growth behavior of cracked aluminum plate repaired with composite patch. Composite Structures, $57(1-4), 323-330$

[28] Sun, C., Klug, J., Arendt, C. (1996). Analysis of cracked aluminum plates repaired with bonded composite patches. AIAA journal, 34(2), 369-374.

[29] Mohammed, S.M.K., Mhamdia, R., Albedah, A., Bouiadjra, B.A.B., Bouiadjra, B.B., Benyahia, F. (2021). Fatigue crack growth in aluminum panels repaired with different shapes of single-sided composite patches. International Journal of Adhesion and Adhesives, 105, 102781.

[30] Wang, Q.Y., Pidaparti, R.M. (2002). Static characteristics and fatigue behavior of composite-repaired aluminum plates. Composite Structures, 56(2), 151-155. 